\title{
Tabelas de esperança de vida e fertilidade de Myzus persicae sobre pimentão em laboratório e casa de vegetação
}

\author{
Leonardo Rodrigues Barbosa $\left({ }^{*}\right)$; César Freire Carvalho ( $\left.{ }^{2}\right)$; Alexander Machado Auad ( $\left.{ }^{3}\right)$; \\ Brígida de Souza (2); Elder Simões de Paula Batista $\left({ }^{4}\right)$
}

(') Embrapa Florestas, Estrada da Ribeira, km 111, Caixa Postal 319, 83411-000 Colombo (PR).

(2) Universidade Federal de Lavras, Caixa Postal 3037, 37200-000 Lavras (MG).

(3) Embrapa Gado de Leite, Rua Eugênio do Nascimento, 610, Dom Bosco, 36038-330 Juiz de Fora (MG).

(4) Universidade Federal de Juiz de Fora, Rua José Lourenço Kelmer, s/n, 36036-900 Juiz de Fora (MG).

(*) Autor correspondente: leonardo@cnpf.embrapa.br

Recebido: 2/jan./2009; Aceito: 9/set./2010.

\begin{abstract}
Resumo
Estudos de tabelas de vida de insetos-praga em diferentes temperaturas auxiliam na compreensão da dinâmica populacional desses organismos. Objetivou-se calcular tabelas de esperança de vida e de fertilidade de Myzus persicae criado em pimentão Capsicum annuum, em diferentes condições térmicas. O estudo foi realizado em câmaras climatizadas, nas temperaturas de 15, 20, 25 e $30^{\circ} \mathrm{C}$, UR de 70 $\pm 10 \%$ e fotofase de 12 horas, e em casa de vegetação em temperaturas oscilantes, com média de $24,9^{\circ} \mathrm{C}$ e UR de 68,1\%. A longevidade máxima de adultos de M. persicae foi maior a $15^{\circ} \mathrm{C}$ (45 dias) e diminuiu a $20^{\circ} \mathrm{C}$ (39 dias), $25^{\circ} \mathrm{C}$ ( 27 dias), $30^{\circ} \mathrm{C}$ (24 dias) e, em casa de vegetação a $24,9{ }^{\circ} \mathrm{C}$ foi de 29,5 dias. A esperança de vida (ex) no primeiro dia de observação foi de 43,76; 35,39; 21,44; 17,67 e 17,03 dias, para as ninfas mantidas a 15, 20, 25, 30 e 24,9 ${ }^{\circ} \mathrm{C}$ respectivamente, tendo a partir daí uma queda acentuada até o fim das observações. Os parâmetros de tabelas de vida e de fertilidade evidenciaram que a temperatura de $25^{\circ} \mathrm{C}$ proporcionou a melhor condição térmica para o crescimento populacional de M. persicae, com maior capacidade de aumentar em número $\left(r_{m}=0,31\right)$ e menor tempo necessário para a população duplicar ( $T D=2,22$ dias). Em casa de vegetação a oscilação térmica afetou o crescimento populacional, proporcionando menor valor de $r_{m}(0,28)$ e maior TD (2,47 dias), comparados àqueles mantidos à temperatura constante equivalente.
\end{abstract}

Palavras-chave: Afídeos, biologia, Capsicum annum, tabela de vida, temperatura.

\section{Fertility and life expectancy tables of Myzus persicae on pepper in laboratory and greenhouse}

\footnotetext{
Abstract

Life table studies of insect pests in different temperatures aid in comprehension on the population dynamics of these organisms. In this study, fertility and life expectancy tables were built for the green peach aphid Myzus persicae reared on pepper Capsicum annuum under different thermal conditions. In laboratory, the study was carried out at 15, 20, 25, and $30{ }^{\circ} \mathrm{C}, 70 \pm 10 \%$ $\mathrm{RH}$ and $12 \mathrm{~h}$ photophase, and in greenhouse at oscillating temperature with average of $24.9{ }^{\circ} \mathrm{C}$ and $68.1 \% \mathrm{RH}$. The longest M. persicae longevity was at $15^{\circ} \mathrm{C}$ (45 days), decreasing at $20^{\circ} \mathrm{C}$ (39 days), $25^{\circ} \mathrm{C}$ ( 27 days) and $30{ }^{\circ} \mathrm{C}(24$ days). Under greenhouse condition at $24.9^{\circ} \mathrm{C}$, the longevity was 29.5 days. The life expectations $\left(e_{x}\right)$ in the first day of observation were 43.76; 35.39; 21.44; 17.67 and 17.03 days for the nymphs maintained at $15,20,25,30$, and $24.9{ }^{\circ} \mathrm{C}$, respectively. From this point on, the $e_{x}$ decreased until the end of the observations. The fertility life table parameters, on a day time scale, indicated that the temperature of $25{ }^{\circ} \mathrm{C}$ provided the best thermal conditions for the growth of $\mathrm{M}$. persicae, with the highest intrinsic rate of natural increase $\left(r_{m}=0.31\right)$ and the shortest time needed for the population to double in size (TD $=2.22$ days). The temperature variation in greenhouse affected the aphid population growth, with a low $r_{\mathrm{m}}$ value (0.28) and a long TD (2.47), compared to those maintained at $25^{\circ} \mathrm{C}$.
}

Key words: Aphids, biology, Capsicum annum, life table, temperature. 


\section{INTRODUÇÃO}

O pimentão Capsicum annuum L. (Solanaceae) é uma hortaliça mundialmente conhecida, destacando-se no Brasil como uma das mais indicadas para ser cultivada em casa de vegetação (TAKAZAKI, 1991), em vista da grande produtividade que pode ser obtida nessas condiçóes (Souza e CASAli, 1984). Esse sistema de cultivo favorece tanto o desenvolvimento da cultura (BLANK et al., 1995), como o incremento de insetos-praga, que podem afetar o rendimento e a qualidade da produçáo (PICANço e Marquini, 1999). Entre as pragas conhecidas, os afídeos têm grande importância, destacando-se Myzus persicae (Sulzer). Esse pulgão está distribuído em todo o mundo e sua importância como vetor de enfermidades viróticas já foi ressaltada em inúmeras pesquisas (Fereres et al., 1993; Borrego et al., 1995).

O estudo do desenvolvimento e dos padrôes de fecundidade e sobrevivência de uma população de insetos, através da elaboração de tabelas de esperança de vida e de fertilidade, é um componente importante para a compreensão da dinâmica populacional desses organismos (SouTHWOOD, 1978). A temperatura está entre os principais fatores que podem condicionar o tamanho da população dos afídeos, ocasionando mudanças na ocorrência sazonal e na dinâmica populacional desses insetos (EASTOp, 1977; Honek e Kocourek, 1990), além de influenciar na longevidade e nas taxas de desenvolvimento e reprodução (Dixon, 1987).

Estudos sobre tabelas de esperança de vida e de fertilidade envolvendo afídeos têm sido desenvolvidos por Bastos et al. (1996); Ricci et al. (2000) e VAsiceK et al. (2001). Cividanes e Souza (2003) investigaram esses parâmetros para $M$. persicae, mantidos em temperaturas constantes; Godoy e Cividanes (2002) para Lipaphis erysimi (Kaltenbach) e Auad e Moraes (2003) para Uroleucon ambrosiae (Thomas) mantidos em temperaturas constantes e variáveis.

A compreensão da relação existente entre as variaçóes de temperatura e os parâmetros biológicos de $M$. persicae é essencial para se estimar o comportamento desse afídeo na cultura do pimentáo. Assim, o objetivo deste trabalho foi determinar as tabelas de esperança de vida e de fertilidade para $M$. persicae em pimentáo em temperaturas constantes em laboratório e variáveis em casa de vegetação.

\section{MATERIAL E MÉTODOS}

\section{Tabelas de vida em laboratório}

Para a elaboração das tabelas de vida de $M$. persicae em laboratório foram utilizadas câmaras climatizadas reguladas a $15,20,25$ e $30^{\circ} \mathrm{C}$, UR de $70 \pm 10 \%$ e fotofase de 12 horas. Como planta hospedeira das ninfas do afí- deo, foram utilizados discos foliares de pimentáo $C$. annuиm cultivar "Ligia" (Fortuna Super) com 4,3 cm de diâmetro.

Para a obtenção de ninfas de primeiro ínstar de $M$. persicae, colocaram-se 3 a 4 fêmeas adultas ápteras, em arenas constituídas por um disco foliar de pimentão acondicionado em placas de Petri de $5 \mathrm{~cm}$ sobre uma solução estéril de ágar/água a $1 \%$ utilizada para manter a turgescência foliar. As arenas foram vedadas com tecido de "voil" e mantidas por aproximadamente 3 horas nas câmaras climatizadas. Após esse período, as fêmeas adultas foram retiradas e 45 ninfas foram individualizadas nas arenas e mantidas nas respectivas temperaturas nas câmaras climatizadas. A cada quatro dias, os insetos eram transferidos para nova arena e submetidos diariamente a observaçóes sob microscópio estereoscópico. Os parâmetros avaliados foram o tempo de desenvolvimento e a mortalidade ninfal, duração do período reprodutivo, o número de ninfas/ fêmea e a longevidade.

As tabelas de vida foram calculadas empregando-se a metodologia sugerida por Silveira Neto et al. (1976). Para elaboração da tabela de esperança de vida determinaram-se os valores de número ou taxa de sobreviventes no início da idade $\mathrm{x}\left(\mathrm{L}_{\mathrm{x}}\right)$; número de indivíduos mortos durante o intervalo etário $\mathrm{x}\left(\mathrm{d}_{\mathrm{x}}\right)$; estrutura etária $\left(\mathrm{E}_{\mathrm{x}}\right)$, que corresponde ao número de indivíduos vivos entre um dia e outro; taxa de sobrevivência $\left(\mathrm{T}_{\mathrm{x}}\right)$, que representa o número de insetos vivos além de determinada idade; esperança de vida para indivíduos de idade $\mathrm{x}\left(\mathrm{e}_{\mathrm{x}}\right)$; e probabilidade de morte na idade $\mathrm{x}\left(100 \mathrm{q}_{\mathrm{x}}\right)$, que indica a probabilidade de ocorrer a morte dos indivíduos antes do tempo estabelecido em $e_{x}$, sendo:

$\mathrm{E}_{\mathrm{x}}=\left[\mathrm{L}_{\mathrm{x}}+\mathrm{L}(\mathrm{x}+1)\right] / 2 ; \mathrm{ex}=\mathrm{T}_{\mathrm{x}} / \mathrm{Lx} ; 100 \mathrm{q}_{\mathrm{x}}=\left(\mathrm{d}_{\mathrm{x}} / \mathrm{L}_{\mathrm{x}}\right) \cdot 100$

Através dos valores de intervalos de idade $(\mathrm{x})$, fertilidade específica $\left(m_{x}\right)$, probabilidade de sobrevivência $\left(l_{x}\right)$ das tabelas de fertilidade de vida, foram calculados os valores da taxa líquida de reprodução $\left(\mathrm{R}_{0}\right)$, intervalo de tempo entre cada geração $(T)$, capacidade inata de aumentar em número $\left(\mathrm{r}_{\mathrm{m}}\right)$, razão finita de aumento $(\lambda)$ e o tempo necessário para a população duplicar em número de indivíduos (TD), sendo:

$\mathrm{R}_{0}=\sum\left(\mathrm{m}_{\mathrm{x}} \cdot \mathrm{l}_{\mathrm{x}}\right) ; \mathrm{T}=\left(\sum \mathrm{m}_{\mathrm{x}} \cdot \mathrm{l}_{\mathrm{x}} \cdot \mathrm{x}\right) /\left(\sum \mathrm{m}_{\mathrm{x}} \cdot \mathrm{l}_{\mathrm{x}}\right) ; \mathrm{r}_{\mathrm{m}}=\log _{\mathrm{e}} \mathrm{R}_{0} / \mathrm{T}=$ $\ln \mathrm{R}_{0} / \mathrm{T} ; \lambda=\mathrm{e}^{\mathrm{r} \mathrm{m}} ; \mathrm{TD}=\ln (2) / \mathrm{r}_{\mathrm{m}}$

\section{Tabelas de vida em casa de vegetação}

Para elaborar as tabelas de esperança de vida e de fertilidade de $M$. persicae em temperaturas variáveis, foram utilizadas plantas de pimentáo da mesma variedade citada anteriormente, com altura média de $15 \mathrm{~cm}$ e 7 a 8 folhas definitivas, plantadas em vasos plásticos com capacidade para $3 \mathrm{~L}$, contendo substrato esterilizado e adubados de acordo com as exigências da cultura. O experimento foi realizado em casa de vegetaçấo revestida com tela antia- 
fídeo nas laterais, e plástico na parte superior, localizada em Lavras (MG), Brasil, no período de dezembro a janeiro. Os dados diários de temperatura e umidade relativa foram registrados através de um termo-higrógrafo e as determinaçôes desses fatores foram feitas empregando-se método citado em Climanálise (1998), aplicando-se as fórmulas:

$$
\begin{aligned}
& \mathrm{T}_{\text {média }}=\mathrm{T}_{9}+\mathrm{T}_{\mathrm{M}}+\mathrm{T}_{\mathrm{x}}+2 \mathrm{~T}_{21} / 5 \\
& \mathrm{U}_{\text {média }}=\mathrm{UR}_{9}+\mathrm{UR}_{15}+2 \mathrm{UR}_{21} / 4
\end{aligned}
$$

sendo: $\mathrm{T}_{\text {média }}=$ temperatura média em ${ }^{\circ} \mathrm{C} ; \mathrm{T}_{9}=$ temperatura às 9 horas; $T_{M}=$ temperatura mínima; $T_{x}=$ temperatura máxima; $T_{21}=$ temperatura às 21 horas; $U_{\text {média }}$ = umidade relativa média em \%; $\mathrm{UR}_{9}=$ umidade relativa às 9 horas; $\mathrm{UR}_{15}=$ umidade relativa às 15 horas; $\mathrm{UR}_{21}=$ umidade relativa às 21 horas.

Para obtenção das ninfas de $M$. persicae, foram mantidas, por aproximadamente 5 horas, em folhas de pimentão, 90 gaiolas confeccionadas com plástico transparente de formato cilíndrico, de $3 \mathrm{~cm}$ de diâmetro e $1,5 \mathrm{~cm}$ de altura, coberta em uma das bordas com tecido "voil" branco e na outra espuma de poliuretano, contendo uma fêmea adulta áptera do pulgão, fixadas por meio de um prendedor de alumínio na proporção de três gaiolas por planta. Após esse período, os adultos foram retirados, e 90 ninfas foram individualizadas e observadas diariamente durante todo o seu desenvolvimento, avaliando-se os mesmos parâmetros estabelecidos para a determinação das tabelas de vida em laboratório, utilizando-se a mesma metodologia citada anteriormente.

\section{RESULTADOS E DISCUSSÃO}

\section{Tabela de esperança de vida em laboratório}

O estágio ninfal nas temperaturas de $15,20,25$ e $30^{\circ} \mathrm{C}$ compreendeu os períodos até 12,5; 8,5; 6,5 e 5,5 dias respectivamente. A mesma espécie de afídeo foi mantida sob o mesmo regime térmico e alimentada com folhas de berinjela e duraçôes médias do estágio ninfal de 9,36; 7,55; 5,89 e 7 dias, da menor para a maior temperatura (CHAgas FILHO et al., 2005). Não foi verificada mortalidade dos insetos nessa fase, proporcionando probabilidade de morte $\left(100 q_{x}\right)$ igual a zero, o que demonstra a não-influência da temperatura sobre esse parâmetro nessa fase de desenvolvimento. A mortalidade iniciou-se apenas após os afídeos tornarem-se adultos (Figura 1). A ausência de mortalidade de ninfas também foi observada por Godor e Cividanes (2002) para L. erysimi em condições de laboratório a 20,25 e $30^{\circ} \mathrm{C}$, diferentemente do constatado por Chagas Filho et al. (2005), estudando o desenvolvimento de ninfas de $M$. persicae sobre folhas de berinjela, com viabilidade de 92, 96, 68 e 8\%, sob 15, 20, 25 e 30 ${ }^{\circ} \mathrm{C}$ respectivamente; observou-se ainda, um quinto estádio de desenvolvimento ninfal sob as temperaturas mais baixas. Evidencia-se, assim, que a duração e viabilidade de M. persicae podem ser afetadas pela temperatura e planta hospedeira às quais os imaturos são submetidos. Portanto, o entendimento das relaçóes entre inseto-praga, planta hospedeira e temperatura é importante para a elaboração das estratégias a serem adotadas para o controle do afídeo, a fim de se prever as épocas de maior ocorrência e a adequaçáo da planta-hospedeira ao incremento populacional do inseto-praga.

A longevidade máxima de adultos de $M$. persicae em plantas de pimentão foi constatada quando mantidos a $15^{\circ} \mathrm{C}$ ( 45 dias), seguido daqueles mantidos a 20,25 e 30 ${ }^{\circ} \mathrm{C}$ longevidades de 39; 27 e 24 dias respectivamente (Figura 1), evidenciando que a longevidade diminuiu com o aumento da temperatura.

A esperança de vida (e $\mathrm{e}_{\mathrm{x}}$ ) de $M$. persicae no primeiro dia de observação foi de 43,76; 35,39; 21,44 e 17,67 dias, para as ninfas mantidas a $15,20,25$ e $30{ }^{\circ} \mathrm{C}$, tendo a partir daí uma queda acentuada até o fim das observaçóes (Figura 1).

$\mathrm{Na}$ fase adulta, a mortalidade dos afídeos mantidos a $15,20,25$ e $30^{\circ} \mathrm{C}$ iniciou-se com 16,$5 ; 22,5 ; 13,5$ e 9,5 dias de observação respectivamente. A esperança de vida (e $\mathrm{e}_{\mathrm{x}}$ observada nesses períodos foi de 27,76; 13,39; 8,44 e 8,67 dias com uma probabilidade de morte $\left(100 q_{\mathrm{x}}\right)$ desses indivíduos de 2,22; 4,44; 2,22 e 4,44\% respectivamente.

\section{Tabelas de fertilidade em laboratório}

O período reprodutivo de $M$. persicae nas temperaturas de 20 e $25^{\circ} \mathrm{C}$ iniciou-se no mesmo dia em que o afídeo se tornou adulto; a 15 e $30^{\circ} \mathrm{C}$ a reproduçâo iniciou-se um dia após o aparecimento dos adultos (Figura 2).

Nas temperaturas de 15 e $20{ }^{\circ} \mathrm{C}$, as maiores taxas de fertilidade específica $\left(m_{x}\right)$ ocorreram entre 28,5 e 29,5 dias (3,20 ninfas/fêmea/dia) e 14,5 e 15,5 dias (5,93 ninfas/fêmea/dia) respectivamente. A $25^{\circ} \mathrm{C}$ essa taxa foi de 7,33 ninfas/fêmea/dia, e ocorreu entre 9,5 e 10,5 dias, enquanto a $30{ }^{\circ} \mathrm{C}$ foi de 4,40 ninfas/fêmea/dia e ocorreu entre 10,5 e 11,5 dias. (Figura 2). Alimentando adultos de M. persicae com berinjela, Michelotтo et al. (2005), constataram fecundidade de 4,3 ninfas/fêmea/dia a $20 \mathrm{e}$ $25^{\circ} \mathrm{C}$.

A sobrevivência $\left(1_{x}\right)$ começou a diminuir a partir de 16,5; 22,5; 13,5 e 9,5 dias nas temperaturas de 15, 20, 25 e $30^{\circ} \mathrm{C}$ respectivamente (Figura 2). As curvas de sobrevivência sugerem que, de modo geral, a taxa de sobrevivência dos afídeos, uma vez alcançada a fase adulta, tende a decrescer com a idade, concordando com as observaçóes efetuadas por VAsiceK et al. (2001) para $M$. persicae a 10 ${ }^{\circ} \mathrm{C}$, usando pimentão como planta hospedeira. 

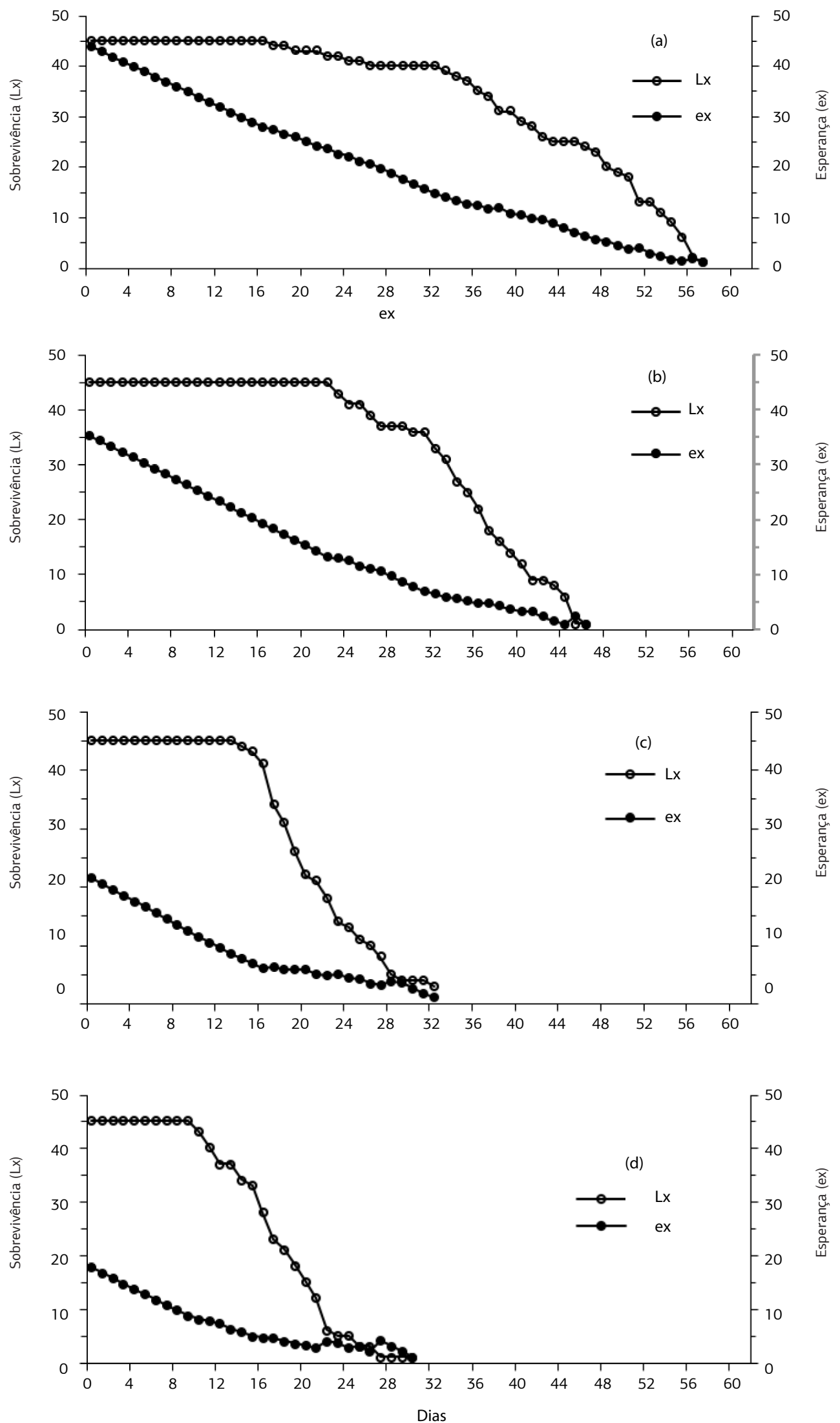

Figura 1. Sobrevivência $\left(\mathrm{L}_{\mathrm{x}}\right)$ e esperança de vida $\left(\mathrm{e}_{\mathrm{\gamma}}\right)$ de Myzus persicae criados em pimentão, submetidos a temperaturas constantes de 15 ${ }^{\circ} \mathrm{C}(\mathrm{a}), 20^{\circ} \mathrm{C}(\mathrm{b}), 25^{\circ} \mathrm{C}$ (c) e $30^{\circ} \mathrm{C}(\mathrm{d})$, UR $70 \pm 10 \%$ e fotofase de 12 horas. 
Myzus persicae em pimentão
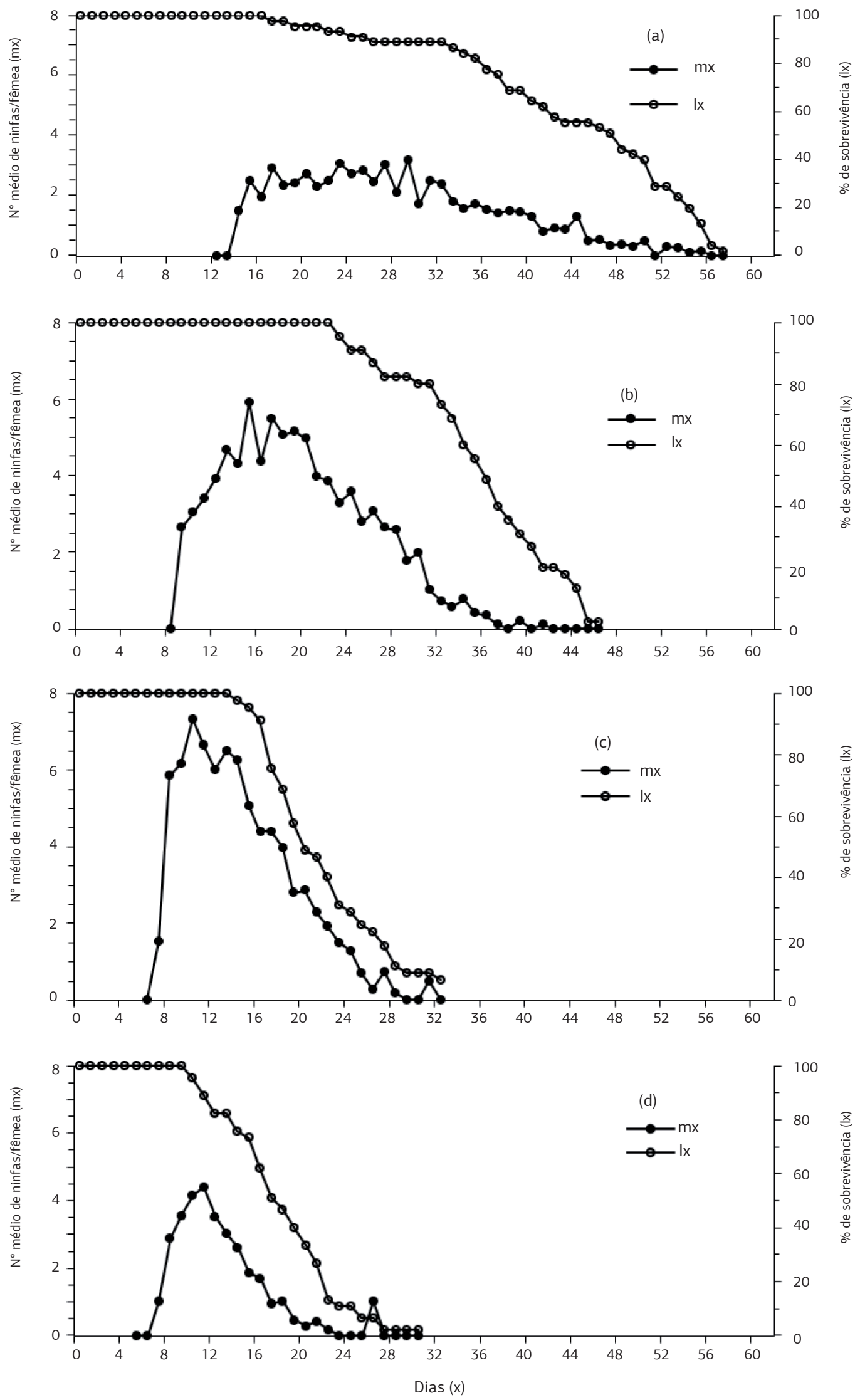

Figura 2. Número médio de ninfas/fêmea $\left(\mathrm{m}_{\mathrm{x}}\right)$ e porcentagem de sobrevivência $\left(1_{\mathrm{x}}\right)$ de Myzus persicae criados em pimentão, submetidos a temperaturas constantes de $15^{\circ} \mathrm{C}(\mathrm{a}), 20^{\circ} \mathrm{C}(\mathrm{b}), 25^{\circ} \mathrm{C}(\mathrm{c})$ e $30^{\circ} \mathrm{C}(\mathrm{d}), \mathrm{UR} 70 \pm 10 \%$ e fotofase de 12 horas.

Bragantia, Campinas, v. 70, n. 2, p.375-382, $2011 \quad 379$ 
Considerando-se os parâmetros de tabelas de fertilidade estimados em laboratório, o intervalo de tempo entre cada geraçáo $(\mathrm{T})$ diminuiu com o aumento da temperatura sendo de 27,07; 19,30; 13,50 e 11,94 dias a 15, 20, 25 e $30{ }^{\circ} \mathrm{C}$ respectivamente (Tabela 1 ). Resultados similares foram observados por Cividanes e Souza (2003), que obtiveram valores de (T) igual a 26,10;20,48; 15,52 e 14,59 dias ao submeterem $M$. persicae a $15,20,23$ e $25^{\circ} \mathrm{C}$.

Os maiores valores da taxa líquida de reprodução de $M$. persicae em plantas de pimentão ocorreram a $20^{\circ} \mathrm{C}$ $\left(\mathrm{R}_{0}=82,73\right)$ e $25^{\circ} \mathrm{C}\left(\mathrm{R}_{0}=67,33\right)$. Nas temperaturas extremas 15 e $30^{\circ} \mathrm{C}$ essa capacidade de aumento populacional de uma geração para outra foi reduzida (Tabela 1), tendendo a promover o menor crescimento populacional do inseto-praga, visto que o incremento populacional depende do número de fêmeas sobreviventes e da produção individual em cada intervalo de tempo.

A capacidade inata de aumentar em número $\left(\mathrm{r}_{\mathrm{m}}\right)$ foi menor a $15^{\circ} \mathrm{C}\left(\mathrm{r}_{\mathrm{m}}=0,15\right)$ e $20^{\circ} \mathrm{C}\left(\mathrm{r}_{\mathrm{m}}=0,23\right)$ e maior a 25 ${ }^{\circ} \mathrm{C}\left(r_{m}=0,31\right)$ e $30^{\circ} \mathrm{C}\left(r_{m}=0,27\right)$ (Tabela 1). O valor de $r_{m}$ observado a $20{ }^{\circ} \mathrm{C}$ é semelhante ao obtido por RicCI et al. (2000) $\left(\mathrm{r}_{\mathrm{m}}=0,25\right)$, estudando $M$. persicae criados em pimentão na mesma temperatura. Entretanto, os valores de $\mathrm{r}_{\mathrm{m}}$ obtidos a 15,20 e $25^{\circ} \mathrm{C}$ foram iguais ou superiores àqueles determinados por Cividanes e SouzA (2003), quando notaramr $\mathrm{r}_{\mathrm{m}}$ de 0,$15 ; 0,18$ e 0,22 , ao submeterem $M$. persicae criados em couve, às respectivas temperaturas. Provavelmente, essas variaçóes podem estar relacionadas à utilização de plantas de couve como hospedeiro para o afídeo e não o pimentáo como efetuado no presente estudo.

A razão finita de aumento $(\lambda)$ foi de 1,$16 ; 1,26 ; 1,37$ e 1,32 ninfas/fêmea/dia, respectivamente, para as temperaturas de $15,20,25$ e $30^{\circ} \mathrm{C}$, evidenciando-se que o maior valor de $\lambda$ foi obtido a $25^{\circ} \mathrm{C}$, enquanto o menor ocorreu a $15^{\circ} \mathrm{C}$, assim como verificado para os valores de $\mathrm{r}_{\mathrm{m}}$ (Tabela 1).

O tempo necessário para a população duplicar em número de indivíduos (TD) nas temperaturas de 15, 20, 25 e $30^{\circ} \mathrm{C}$ foi de 4,65 ; 3,03; 2,22 e 2,53 dias respectivamente, enfatizando que fêmeas a $25^{\circ} \mathrm{C}$ duplicaram mais rapidamente que aquelas mantidas outras temperaturas (Tabela 1).

\section{Tabela de esperança de vida em casa de vegetação}

Os estágios ninfal e adulto de $M$. persicae compreenderam os períodos de 6,5 e 23 dias, respectivamente, quando mantidos em temperatura oscilantes com média diária de $24,9^{\circ} \mathrm{C}$. A esperança de vida $\left(\mathrm{e}_{\mathrm{x}}\right.$ ) variou de 17,3 dias para 11,78 dias no estágio ninfal e de 10,78 dias para 0,5 dia no estágio adulto, sendo esses valores constatados, respectivamente, no primeiro e aos 6,5 dias de observação para as ninfas e aos 7,5 e 29,5 dias para os adultos (Figura 3a).

As maiores taxas de mortalidade $\left(\mathrm{d}_{\mathrm{x}}\right)$ desse afídeo ocorreram entre 4,5 e 5,5 dias para o estágio ninfal e 12,5 e 13,5 dias para o adulto, quando 2 e 14 indivíduos morreram com probabilidades de morte $\left(100 \mathrm{q}_{\mathrm{x}}\right)$ de, respectivamente, $2,5 \%$ e $17,5 \%$, para cada estágio (Figura $3 a$ ).

\section{Tabela de fertilidade em casa de vegetação}

O período reprodutivo iniciou-se aos 7,5 dias, por ocasião da emergência das fêmeas verificando-se apenas um dia de período pré-reprodutivo (Figura 3b). A duração do período reprodutivo foi de 22 dias e a maior fertilidade específica $\left(\mathrm{m}_{\mathrm{x}}\right)$ ocorreu entre 10,5 e 11,5 dias com produção de 4,89 ninfas/fêmea/dia. A taxa de sobrevivência $\left(\mathrm{l}_{\mathrm{x}}\right)$ esteve sempre acima de $90 \%$ até o 11,5 dia, a partir dessa data houve uma queda acentuada na mesma (Figura $3 b$ ).

$\mathrm{O}$ intervalo de tempo entre cada geração $(\mathrm{T})$ foi de 12,6 dias, com uma taxa líquida de reprodução $\left(\mathrm{R}_{0}\right)$ de 34,42, indicando que $M$. persicae, desenvolvido sobre pimentão em casa de vegetação, possui a capacidade de aumentar aproximadamente 34 vezes a sua população a cada geraçáo, em pouco mais de 12 dias (Tabela 1).

A capacidade inata de aumentar em número $\left(\mathrm{r}_{\mathrm{m}}\right)$ foi de 0,28 e a razão finita de aumento $(\lambda)$ foi de 1,32 ninfas/fêmea/dia e o tempo necessário para a população duplicar em número de indivíduos (TD) foi de 2,47 dias (Tabela 1). Os valores de $r_{m}$ e de $\lambda$ registrados em casa de vegetação foram menores que aqueles verificados em laboratório sob temperatura constante de $25^{\circ} \mathrm{C}$, indicando que o crescimento populacional dos pulgôes foi afe-

Tabela 1. Parâmetros de tabela de vida de fertilidade de Myzus persicae criados em pimentão em condiçóes de laboratório e casa de vegetaçáo. Lavras (MG)

\begin{tabular}{|c|c|c|c|c|c|}
\hline Temperaturas $\left({ }^{\circ} \mathrm{C}\right)$ & & & âmet & & \\
\hline Laboratório & $\mathbf{T}$ & $\mathbf{R}_{0}$ & $r_{m}$ & $\lambda$ & TD \\
\hline 15 & 27,07 & 57,43 & 0,15 & 1,16 & 4,65 \\
\hline 20 & 19,30 & 82,73 & 0,23 & 1,26 & 3,03 \\
\hline 25 & 13,50 & 67,33 & 0,31 & 1,37 & 2,22 \\
\hline 30 & 11,94 & 26,51 & 0,27 & 1,32 & 2,53 \\
\hline $\begin{array}{l}\text { Casa de vegetação } \\
17,8 ; 24,9 ; 36,6^{(1)}\end{array}$ & 12,60 & 34,42 & 0,28 & 1,32 & 2,47 \\
\hline
\end{tabular}

$\mathrm{T}$ = intervalo de tempo entre cada geraçăo (dias); $\mathrm{R}_{0}=$ taxa líquida de reprodução; $\mathrm{r}_{\mathrm{m}}=$ capacidade inata de aumentar em número; $\lambda=$ razāo finita de aumento; $\mathrm{TD}=$ tempo necessário para populaçáo duplicar em número de indivíduos (dias).

(1) Médias das temperaturas em ${ }^{\circ} \mathrm{C}$, mínima, média e máxima registradas em casa de vegetaçăo no transcorrer do experimento. 
(a)

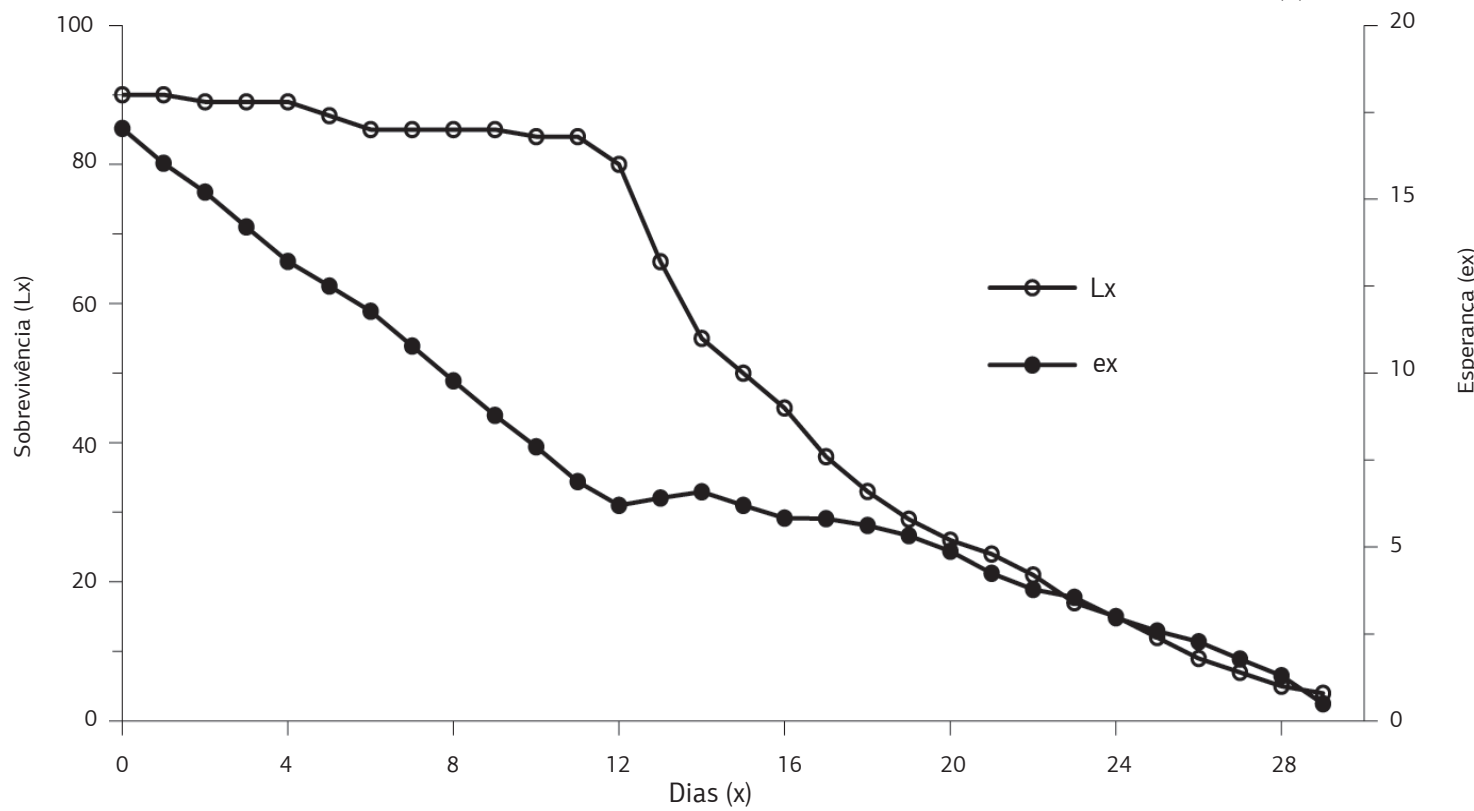

(b)

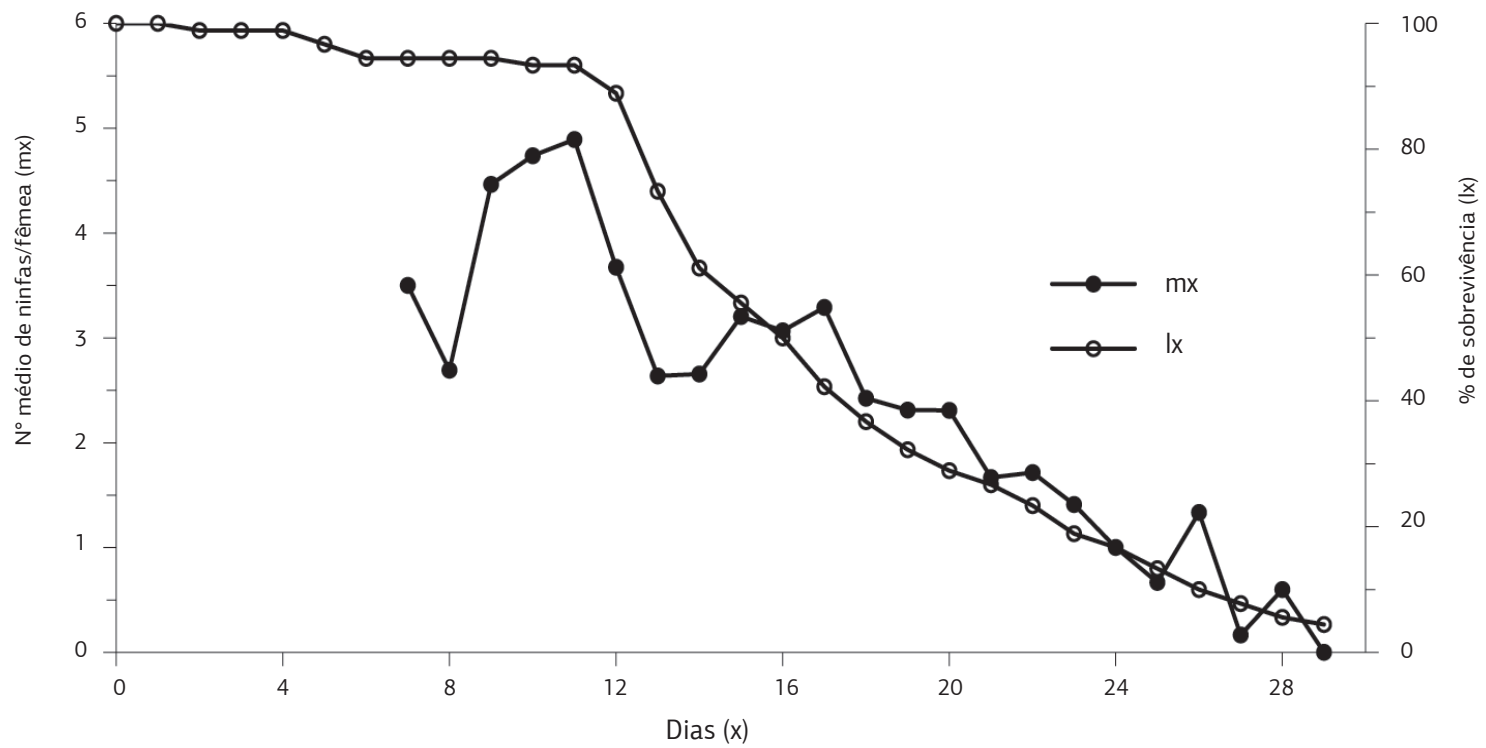

Figura 3. Sobrevivência $\left(\mathrm{L}_{\mathrm{x}}\right)$ e esperança de vida $\left(\mathrm{e}_{\mathrm{x}}\right)(\mathrm{a})$ e número médio de ninfas/fêmea $\left(\mathrm{m}_{\mathrm{x}}\right)$ e porcentagem de sobrevivência $\left(\mathrm{l}_{\mathrm{x}}\right)$ (b) de Myzus persicae criados em pimentão, submetidos a temperaturas variáveis em casa de vegetação, com média de $24,9{ }^{\circ} \mathrm{C}$.

tado quando foram mantidos em regime de temperatura variável na casa de vegetação, a despeito a temperatura média ser próxima à ideal $\left(25^{\circ} \mathrm{C}\right)$. Provavelmente, essas diferenças podem estar relacionadas à amplitude térmica $\mathrm{e}$ às faixas de temperaturas preponderantes $\left(15-20^{\circ} \mathrm{C} \mathrm{e}\right.$ 20-25 ${ }^{\circ} \mathrm{C}$ ) às quais os pulgóes foram expostos na casa de vegetação (Figura 4). Essas observações não confirmam as feitas por Mironidis e Savopoulou-Soultani (2008), que registraram desenvolvimento mais rápido de Helicoverpa armigera (Hubner) (Lepidoptera: Noctuidae), sob regime térmico alternante, do que constante sob mesma média $\left(25^{\circ} \mathrm{C}\right)$; tais autores justificaram essa

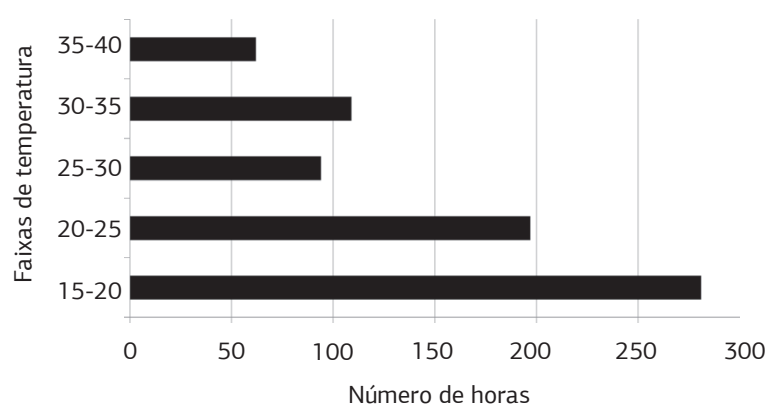

Figura 4. Faixas de temperaturas (horas) verificadas em casa de vegetaçáo, período de dezembro a janeiro. 
aceleração baseando-se na hipótese que temperaturas alternantes satisfariam a temperatura ótima dos diferentes componentes envolvidos nos processos fisiológicos do inseto, favorecendo o desenvolvimento.

Considerando-se que o efeito da temperatura alternante sobre o crescimento populacional pode ser variável dependendo do inseto, deve-se ter cautela ao extrapolar resultados de tabelas de vida obtidos em laboratório, usualmente sob temperaturas constantes, para condições de campo ou casa de vegetação, com temperatura variável.

\section{CONCLUSÃO}

O pulgão Myzus persicae mantido em plantas de pimentáo possui potencial de crescimento populacional maior a $25^{\circ} \mathrm{C}$. O crescimento populacional de Myzus persicae é influenciado quando os insetos são mantidos em regimes de temperaturas constantes e variáveis, mesmo considerando a temperatura média igual.

\section{REFERÊNCIAS}

AUAD, A.M.; MORAES, J.C. Biological aspects and life table of Uroleucon ambrosiae (Thomas, 1878) as a function of temperature. Scientia Agricola, v.60, p.657-662, 2003.

BASTOS, C.S.; PICANÇO, M.C.; LEITE, G.L.D.; ARAÚJO, J.M. Tabelas de fertilidade e de esperança de vida de Myzus persicae (Sulzer) (Homoptera: Aphididae) em couve-comum. Científica, v.24, p.187-197, 1996.

BLANK, A.F.; SOUZA, R.J.; GOMES, L.A.A. Produção de pimentão em estufa. Lavras: UFLA, 1995. 15p. (Circular, 55)

BORREGO, J.V.M.; ESPAÑA, B.P.; PITARCH, V.B. Enfermidades de las hortalizas. Espanha: Mundi-Prensa, 1995. 576p.

CHAGAS FILHO, N.R.; MICHELOTTO, M.D.; SILVA, R.A.; BUSSOLI, A.C. Desenvolvimento ninfal de Myzus persicae (Sulzer, 1776) (Hemiptera: Aphididae) sobre beringeja em diferentes temperaturas. Bragantia, v.64, p.257-262, 2005.

CIVIDANES, F.J.; SOUZA, V.P. Exigências térmicas e tabelas de vida de fertilidade de Myzus persicae (Sulzer) (Hemiptera: Aphididae) em laboratório. Neotropical Entomology, v.32, p.413419, 2003.

CLIMANÁLISE. Boletim de Monitoramento e Análise Climática, v.13, p.45, 1998.
DIXON, A.F.G. Partenogenetic reproduction and the rate of increase in aphids. In: MINKS, A. K.; HARREWINJN P. (Ed.). World crop pests. Aphids: Their biology, natural enemies and control. Amsterdam: Elsevier, 1987. p.269-287.

EASTOP, V.F. Worldwide importance of aphids as virus vectors. In: HARRIS, K. F.; MARAMOROSCH, K (Ed.). Aphids as virus vectores. New York: Academic Press, 1977. p.3-62.

FERERES, A.; PEREZ, P.; GEMENO, C.; PONZ, F. Transmission do Spanish pepper and potato PVY isolates by aphid (Homoptera: Aphididae) vectors: epidemiological implications. Environmental Entomology, v.22, p.1260-1265, 1993.

GODOY, K.B.; CIVIDANES, F.J. Tabelas de esperança de vida e de fertilidade de Lipaphis erysimi (Kalt.) (Hemiptera: Aphididae) em condiçóes de laboratório e campo. Neutropical Entomology, v.31, p.41-48, 2002.

HONEK, A.; KOCOUREK, F. Temperature and development time in insects: A general relationship between thermal constants. Zoologische Jahrbiicher Systematik, v.117, p.401-439, 1990.

MICHELOTTO, M.D.; CHAGAS FILHO, N.R.; SILVA, R.A.; BUSOLI, A.C. Longevidade e parâmetros reprodutivos de Myzus persicae (Sulzer, 1776) (Hemiptera: Aphdidae) sobre berinjela em diferentes temperaturas. Ciência Rural, v.35, p.788-793, 2005.

MIRONIDIS, G.K.; SAVOPOULOU-SOULTANI, M. Development, survivorship, and reproduction, of Helicoverpa armigera (Lepidoptera: Noctuidae) under constant and alternating temperatures. Environmental Entomology, v.37, p.16-28, 2008.

PICANÇO, M.; MARQUINI, F. Manejo integrado de pragas de hortaliças em ambiente protegido. Informe Agropecuário, v.20, p.126-133, 1999.

RICCI, E.; La ROSA, F.R.; VASICEK, A. Demografía del "pulgón verde del duraznero" Myzus persicae (Sulzer) (Homoptera: Aphidoidea) sobre pimiento (Capsicum annum) en condiciones de laboratorio. Ceiba, v.41, p.17-20, 2000.

SILVEIRA NETO, S.; NAKANO, O.; BARBIN, D.; VILLA NOVA, N. Manual de ecologia dos insetos. São Paulo: Agronômica Ceres, 1976. 419p.

SOUTHWOOD, T.R.E. Ecological methods. 2.ed. New York: Chapman and Hall, 1978. 524p.

SOUZA, R.J.; CASALI, V.W.D. Cultivares de pimentão e pimenta. Informe Agropecuário, v.10, p.14-18, 1984.

VASICEK, A.L.; De La ROSSA, F; PAGLIONI, A. Aspectos biológicos y poblacionale de Aulacorthum solani, Myzus pesicae y Macrosiphium euphorbiae (Homoptera: Aphidoidea) en pimiento (Capsicum annum L.). Boletín de Sanidad Vegetal-Plagas, v.27, p.439-446, 2001. 